\title{
Y-stent-assisted coil embolization of cerebral aneurysms
}

\author{
Lee A. Tan, M.D., Andrew K. Johnson, M.D., Kiffon M. Keigher, APN, \\ Roham Moftakhar, M.D., and Demetrius K. Lopes, M.D. \\ Department of Neurosurgery, Rush University Medical Center, Chicago, Illinois
}

\begin{abstract}
Y-stent-assisted coiling is a technique used by neuroendovascular surgeons to treat complex, wide-necked, bifurcation aneurysms in locations such as basilar tip and middle cerebral artery bifurcation. Several recent studies have demonstrated low complication rate and favorable clinical and angiographic outcomes. The Y-stent technique is illustrated here in detail and the intraoperative nuances are also discussed to minimize potential complications associated with technique.

The video can be found here: http://youtu.be/77pEmqx_fyQ.

(http://thejns.org/doi/abs/10.3171/2014.V2.FOCUS14176)
\end{abstract}

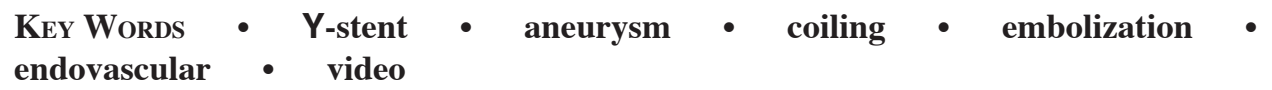

Manuscript submitted April 30, 2014.

Accepted June 3, 2014.

Please include this information when citing this paper: DOI: 10.3171/2014.V2.FOCUS14176.

Address correspondence to: Dr. Lee A. Tan, Department of Neurosurgery, Rush University Medical Center, 1725 W. Harrison St. Suite 855, Chicago, Illinois60612.email: lee_tan@rush.edu. 